\title{
Surveys of gas hydrates in the Okhotsk Sea offshore of Abashiri and soil properties of sea bottom sediments
}

\author{
Satoshi Yamashita ${ }^{\text {i) }}$, Shintaro Yamasaki ${ }^{\text {ii) }}$, Hiroki Ohshima ${ }^{\text {iii) }}$ and Satsuki Kataoka ${ }^{\text {iv }}$
}

\begin{abstract}
i) Professor, Dept. of Civil and Environmental Eng., Kitami Institute of Technology, 165 Koen-cho, Kitami 090-8507, Japan. ii) Assistant Prof., Dept. of Civil and Environmental Eng., Kitami Institute of Technology, 165 Koen-cho, Kitami 090-8507, Japan. iii) Graduate Student, Dept. of Civil and Environmental Eng., Kitami Institute of Technology, 165 Koen-cho, Kitami 090-8507, Japan. iv) Assistant Prof., Dept. of Civil Eng., Kobe University, Rokkodai 1-1, Nada-ku, Kobe 657-8501, Japan.
\end{abstract}

\begin{abstract}
In this study, to clarify the distribution of gas-hydrate and its formative environment of seabed methane, and to evaluate the potential as resource of gas-hydrate, the geologic surveys were conducted by NT13-20 and OS263 cruises covering a wide area of Abashiri and Shari Submarine Canyons in the Okhotsk Sea. The conducted investigations are the seismic geologic survey, the bathymetry and the gas-flare observation by an echo sounder, and core sampling of sea-bottom sediments. Moreover, to examine the soil properties of sea bottom sediments, some kinds of shipboard tests such as handy vane shear and cone penetration tests, and physical properties tests such as water content and grain size distribution tests, were performed for the samples.
\end{abstract}

Keywords: gas hydrate, marine sediment, Okhotsk Sea, sea bottom topography

\section{INTRODUCTION}

Gas hydrates are attracting attention as a future energy resource, with projects aimed at their utilization under way in various countries. In Japan, the MH21 R\&D project in the Nankai Trough region has entered its production test stage. On the other hand, in 1995, when Japan pioneered a project for the utilization of gas hydrates, clear bottom-simulating reflectors (BSR) were confirmed also at the Kitami-Yamato Bank in the Okhotsk Sea offshore of Abashiri, indicating the possible existence of gas hydrates there (Satoh et al. 1996). In addition to this, seismic survey records collected by the National Institute of Advanced Industrial Science and Technology (AIST) during a cruise for their GH01 project in 2001 also confirmed noticeable BSR (Noda et al. 2009). Despite such indications of gas hydrates in the Okhotsk Sea offshore of Abashiri, the actual resource conditions have not been made clear due to inadequate investigation.

On another front, with some regions in the Okhotsk Sea offshore of Abashiri as the target, three surveys (TK11: Yamashita et al. 2012; UT12 and OS249: Ogawa et al. 2013) were implemented beginning in 2011 in the regions shown in Figure 1. To observe the seabed topography and gas flares, these surveys used a quantitative echo sounder and performed coring in the areas surrounding observed gas flares; thus, the survey scope was limited. Surveys of the structures beneath the seabed, which are needed to understand the potential quantity of gas hydrates, have not been conducted.

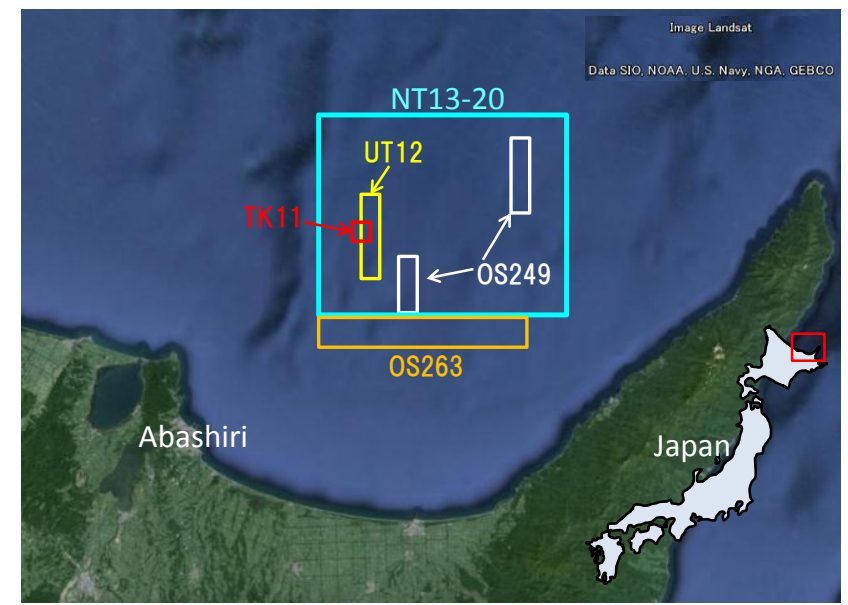

Fig. 1. Survey regions in the Okhotsk Sea off Abashiri.

The Japan Agency for Marine-Earth Science and Technology (JAMSTEC) therefore conducted a survey (NT13-20) in September 2013 that covered the areas of the three abovementioned surveys, using the research vessel Natsushima. The survey was conducted in an area of approximately $30 \mathrm{~km}$ around, as shown in Figure 1. It included a single-channel sonic survey of the structure beneath the seabed, the observation of seabed topography and gas flares using a multi-beam sounding device and quantitative echo sounder, and the sampling of seabed sediments. In addition, a survey 
(OS263) using the Oshoro-Maru, the research training ship of the Hokkaido University, was conducted in November 2013 such as to supplement the scope of the Natsushima survey. Below is an explanation of survey results and of the results of various physical and mechanical tests on sediments retrieved from the seabed layer.

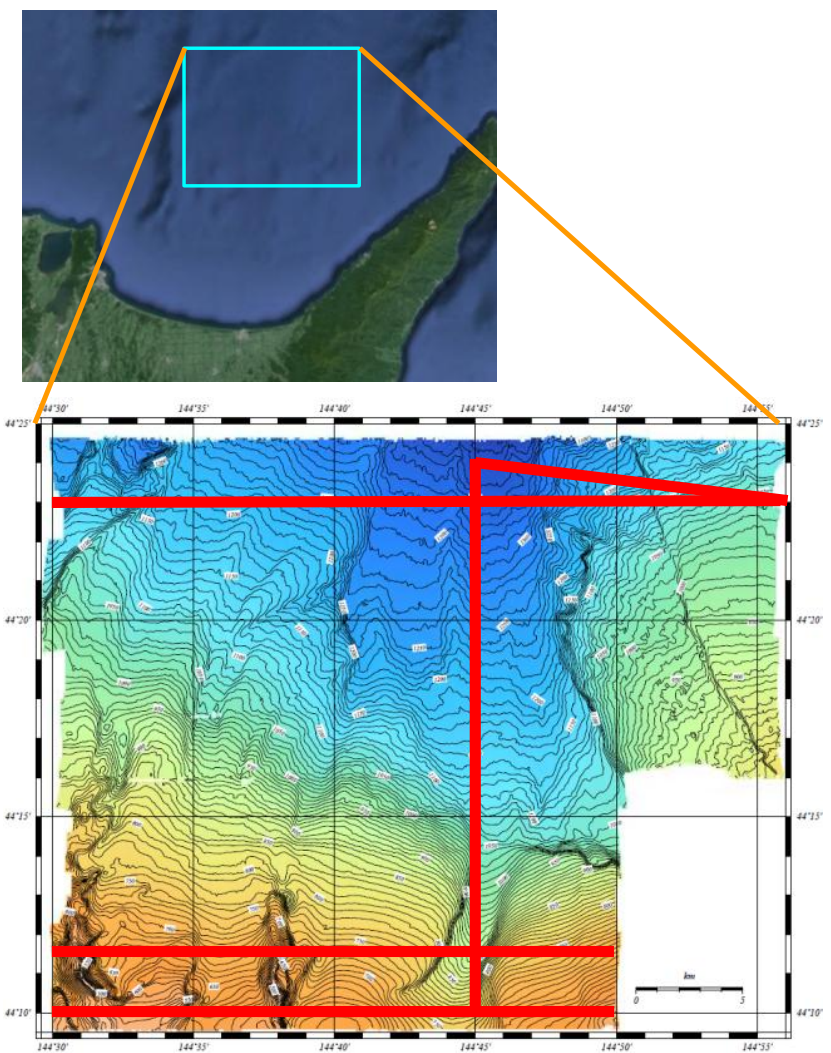

Fig. 2. Seismic survey (SCS) lines.

\section{SEISMIC SURVEY}

In the NT13-20 survey, a single-channel sonic (SCS) survey was conducted along the 5 survey lines shown in Figure 2. Figure 3 shows an example of a longitudinal sectional drawing from the sonic survey (north-south survey line). The dotted lines in the picture indicate the BSR, which can be confirmed to run along almost the full length of the survey line. On the left-hand side of the longitudinal sectional drawing (the north side of survey line), the two-way travel time on the seabed surface was $1,880 \mathrm{~ms}$, and with a water depth of about $1,400 \mathrm{~m}$ at that location, the sound speed was approx. $1,500 \mathrm{~m} / \mathrm{s}$. If the sound speeds in water and shallow underground are assumed to be equal, the depth of the BSR is $142.5 \mathrm{~m}$, since the two-way travel time from the seabed surface on the left side of the longitudinal sectional drawing to the BSR is about 190 ms. Since the two-way travel time from the seabed surface on the right side of the longitudinal sectional drawing to the BSR is about $140 \mathrm{~ms}$, the depth of the BSR is $105 \mathrm{~m}$. In all the other survey lines, relatively noticeable BSR was confirmed, which indicates a high probability that gas hydrates exist extensively along the coast of Abashiri.

Regarding the BSR depth, Hayashi et al. (2010) assume that BSR at a depth of $1,400 \mathrm{~m}$ on the Abashiri coast are $160 \mathrm{~m}$ beneath the seabed, a figure that corresponds with the results of this survey. Also, the depths at which BSR appear on the Abashiri coast are shallow: $1 / 2$ to $1 / 3$ those for the Nankai Trough. Hayashi et al. attribute this to the region's high heat flow in the earth's crust and to the geothermal gradient. When estimating the geothermal gradient from the BSR depth based on Ashi and Taira's (1993) method and supposing that at the left side (north side) of the longitudinal sectional drawing the water pressure is 15.5 $\mathrm{MPa}$ and the salinity is $3 \%$, then the phase boundary temperature of the hydrate and gas obtained from the phase equilibrium condition indicated by Sloan and Koh (2007) becomes $16^{\circ} \mathrm{C}$. Since the water temperature at the seabed surface is about $2^{\circ} \mathrm{C}$, the geothermal gradient is $98 \mathrm{mK} / \mathrm{m}$. In the same way, calculation at the right side of the longitudinal sectional drawing comes out to $88 \mathrm{mK} / \mathrm{m}$. This value is similar to the average value for the Joetsu coast (Machiyama et al. 2009) of the Japan Sea, where surface layer hydrates have been confirmed and the geothermal gradient is considered to be relatively high.

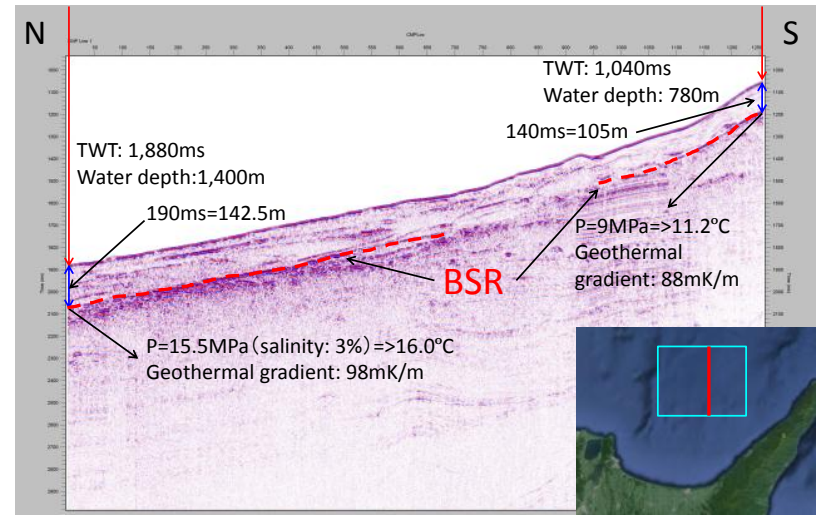

Fig. 3. An example of seismic reflection profile (north-south survey line).

\section{SEABED TOPOGRAPHY AND GAS FLARE OBSERVATION SURVEYS}

The NT13-20 survey used a multi-beam sounding device and a quantitative echo sounder along 21 survey lines (at approx. 1.5-km intervals) drawn east-west within the range shown in Figure 2; the OS263 survey used a quantitative echo sounder along 21 survey lines (at approx. 185-m intervals) drawn east-west within the range shown in Figure 1 in surveys. An example of the gas flares observed by quantitative echo sounder in the OS263 survey is shown in Figure 4. Figure 5 shows the seabed topographical map of the survey area created by combining the sounding data obtained from the NT13-20 survey, which used a multi-beam sounding device and a quantitative echo sounder, and the 
sounding data obtained from the OS269 survey, which used a quantitative echo sounder. The " $X$ " marks show locations, including from previous surveys, where gas flares were observed by multi-beam sounding device and quantitative echo sounder.

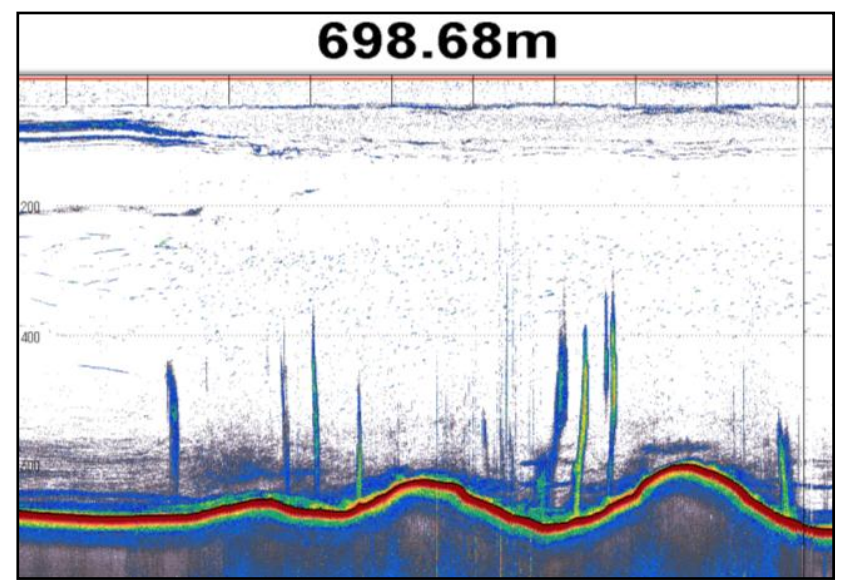

Fig. 4. An example of gas flares observed by quantitative echo sounder.

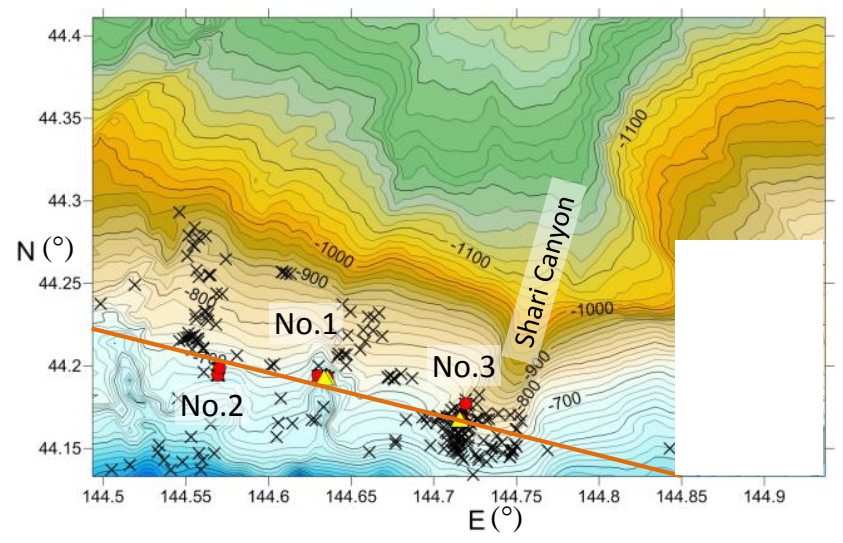

Fig. 5. Gas flare observation points and sampling sites.

In the survey region, gas flares were not observed on the sea side, where water depths were greater than on the land side; instead, they tended to be confirmed in areas on the land side, with water depths of about 500to $700-\mathrm{m}$. Gas flares were easily visible at the southern edge of the Shari submarine canyon and surrounding the mud volcano to its west, and a hydrogen sulfide odor was detected at sea near the southern edge of the Shari submarine canyon. Including past surveys, the number of locations where gas flares have been confirmed is about 200. Further, survey line intervals were $1.5 \mathrm{~km}$ for the NT13-20 survey to the north of lat. $44.17^{\circ} \mathrm{N}$ and $185 \mathrm{~m}$ for the OS263 survey to the south of lat. $44.17^{\circ} \mathrm{N}$. The survey line seabed width that the quantitative echo sounder is able to observe in one survey line is less than $100 \mathrm{~m}$. When conducted at higher density, there is a higher probability that more gas flares will be observed.

The following reasons may be considered as to why gas flares were observed at these relatively shallow locations. As shown in Figure 3, BSR occur approximately $100 \mathrm{~m}$ below the seabed on the land side (the southern side), in contrast to the sea side (the northern side), where BSR are found approximately $140 \mathrm{~m}$ below the seabed. Accordingly, it is thought that the layer of the gas hydrate's stability region on the land side is thin and that the layer receives a supply of free gas from the lower BSR, thus creating a condition where gas is easily emitted. It may also be assumed that gas emission was notable since the water is shallower as one moves landward and is therefore closer to the phase equilibrium boundary in the seabed layer.

Table 1. Details of cores.

\begin{tabular}{lllll}
$\begin{array}{l}\text { Core } \\
\text { Name }\end{array}$ & Latitude, N & Longitude, E & $\begin{array}{l}\text { Water } \\
\text { depth }(\mathrm{m})\end{array}$ & $\begin{array}{l}\text { Core } \\
\text { length }(\mathrm{cm})\end{array}$ \\
\hline $\mathrm{PC} 01^{*}$ & $44^{\circ} 11.577^{\prime}$ & $144^{\circ} 38.137^{\prime}$ & 485 & 150 \\
\hline $\mathrm{PC} 02^{*}$ & $44^{\circ} 11.583^{\prime}$ & $144^{\circ} 38.010^{\prime}$ & 483 & 192 \\
\hline $\mathrm{PC} 03$ & $44^{\circ} 11.650^{\prime}$ & $144^{\circ} 37.803^{\prime}$ & 560 & 364 \\
\hline $\mathrm{PC} 04$ & $44^{\circ} 11.666^{\prime}$ & $144^{\circ} 34.172^{\prime}$ & 589 & 256 \\
\hline $\mathrm{PC} 05$ & $44^{\circ} 11.930^{\prime}$ & $144^{\circ} 34.220^{\prime}$ & 604 & 434 \\
\hline $\mathrm{PC} 06^{*}$ & $44^{\circ} 10.058^{\prime}$ & $144^{\circ} 42.941^{\prime}$ & 690 & 46 \\
\hline $\mathrm{PC} 07$ & $44^{\circ} 10.621^{\prime}$ & $144^{\circ} 43.158^{\prime}$ & 730 & 434 \\
\hline $\mathrm{GC} 08$ & $44^{\circ} 10.062^{\prime}$ & $144^{\circ} 42.942^{\prime}$ & 685 & 133 \\
\hline
\end{tabular}

*: gas hydrate contained core

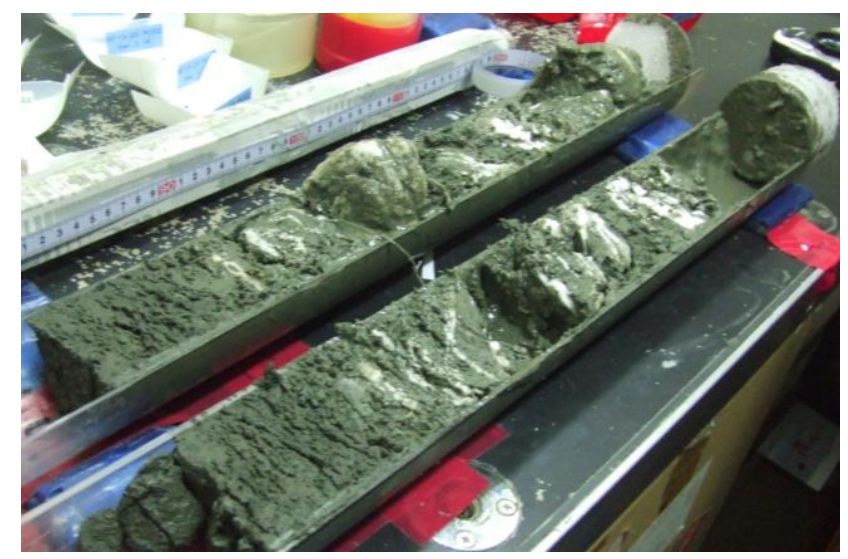

Photo 1. An example of collected gas hydrate.

\section{CORE SAMPLING OF SEA-BOTTOM SEDIMENT AND SHIPBOARD TESTING}

Corers were used to sample sediments of the seabed layer at locations where gas flares were detected. Piston corers (PC, $4 \mathrm{~m}$ and $6 \mathrm{~m}$ in length) and a gravity corer (GC, $4 \mathrm{~m}$ in length) were used. Both types of corers use a double-tube system, with a vinyl chloride pipe (75 $\mathrm{mm}$ in inner diameter) as the inner tube. The latitude and longitude of the sampling locations, the water depth and the core lengths are shown in Table 1. Coring locations are marked with $\bullet$, and locations where gas hydrates were detected in core samples are marked with $\boldsymbol{\Delta}$ (Figure 5). From two cores (PC01, PC02) at location No.1 and one core (PC06) at location No.3 in Figure 5, layered or agglomerated gas hydrates were confirmed at depths of roughly a few $\mathrm{cm}$ to $2 \mathrm{~m}$. Gas hydrates that were actually collected are shown in Photo 1. 
After a corer was pulled aboard the ship, its internal tube was cut at every $1 \mathrm{~m}$ and then split in half vertically. At 5- to $15-\mathrm{cm}$ intervals, samples were collected to determine moisture content and handy cone penetration tests (apex angle: $30^{\circ}$; cone diameter: 9 $\mathrm{mm}$; penetration depth: $16.8 \mathrm{~mm}$ ) and handy vane shear tests (vane width: $10 \mathrm{~mm}$; height: $20 \mathrm{~mm}$; penetration depth: $30 \mathrm{~mm}$ ) (Yamashita et al. 2011) were conducted. In cores where gas hydrates were collected, tests were conducted in parts of the core where the hydrates did not exist.

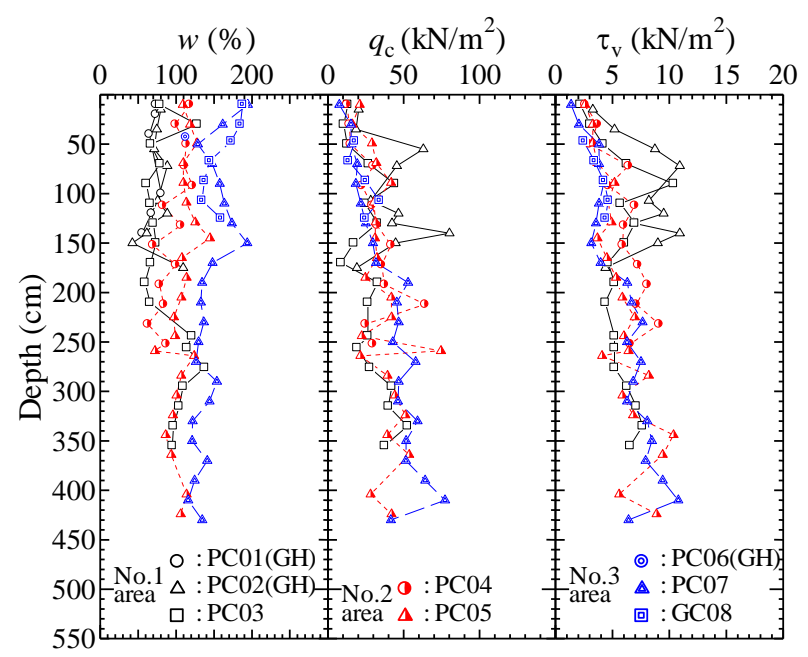

Fig. 6. Shipboard test results.

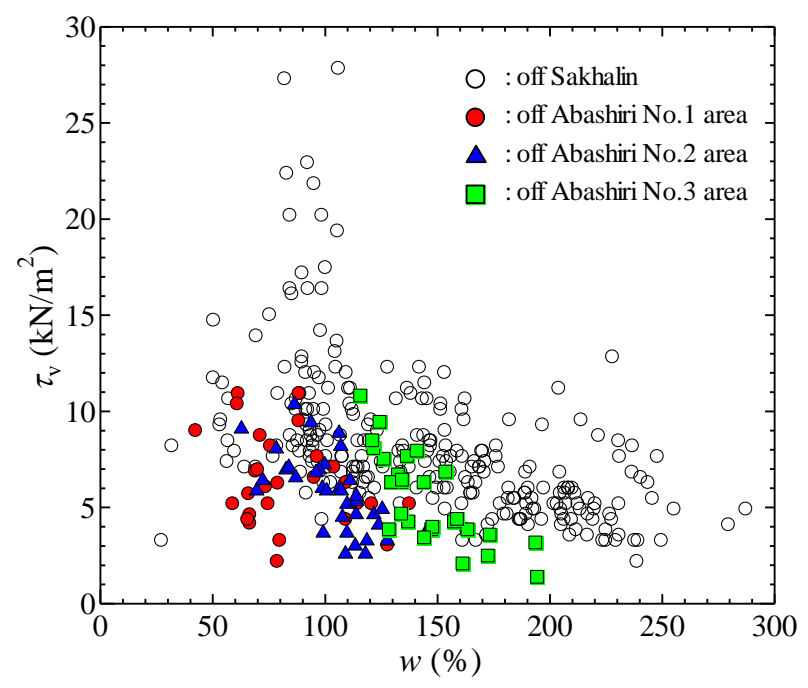

Fig. 7. Relations of vane shear strength and water content.

Figure 6 shows the moisture content $w$, obtained from the collected samples, and the cone penetration resistances $q_{\mathrm{c}}$ and vane shear strengths $\tau_{\mathrm{v}}$, obtained through shipboard testing, plotted against depths from the seabed. From the collected cores, only a small amount of samples were obtained for PC01 and PC06; therefore, no strength tests were conducted. Figure 7 shows the relationship between vane shear strength and moisture content.
A comparison of the cores in terms of the strength properties and moisture content, which differ by sampling location, found that at depths from the seabed surface to $2.5 \mathrm{~m}$ below the surface, the moisture content was lower in samples collected at location No.1 and higher in samples collected at location No.3. Regarding the strength properties of the samples, not much difference was recognized among the sampling locations, except at location No.1 between the depths from the seabed to $2 \mathrm{~m}$, where the strengths were higher. Also from the relationship between the vane shear strength and the moisture content shown in Figure 7, one can see that although strength did not differ by sampling location, the moisture content differed greatly. The relationship between vane shear strength and moisture content of samples collected on the eastern coast of Sakhalin Island in the Okhotsk Sea (Yamashita et al. 2011) is also shown in Figure 7, and it can be seen that the seabed sediment in the Okhotsk Sea offshore of Abashiri tends to have lower strength.

The fact that the moisture content and strength properties differed by sampling location, as described above, is attributed to the topographical factors of these locations. Figure 8 is a cross section of the seabed along the line traversing the locations shown in Figure 5 where coring was performed. Location No.1, where gas hydrates were sampled, is close to the apex of a mud volcano roughly $150 \mathrm{~m}$ in relative elevation, whereas No.2 has a mound terrain but is lower in relative elevation than location No.1. However, gas hydrates were collected at location No.3, whose terrain is even or consists of valleys.

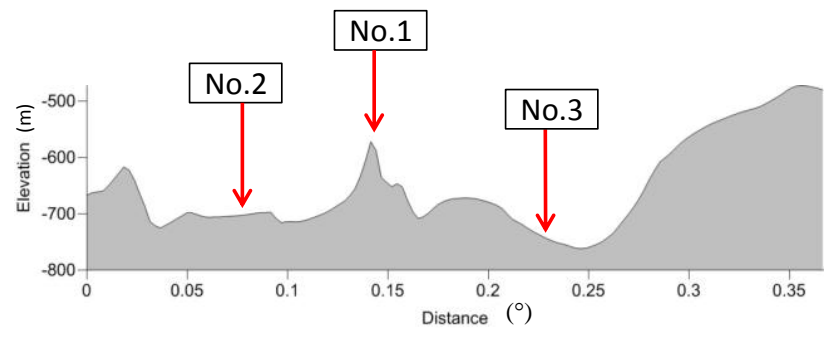

Fig. 8. A cross section of the seabed at coring points.

Figure 9 shows, by depth, the clay, silt and sand content from the results of grain size distribution test that used a laser diffraction particle size distribution analyzer (Shimadzu SALD-2300). Sand content in the sample collected from location No.1, which is a mud volcano apex, between the depths of the seabed surface and $2 \mathrm{~m}$ below was greater than that in samples from other locations. Since this location saw the most active gas emissions (gas flares) in the area surveyed, it is thought that the grading caused by spouts of sediments from the depths or resedimentation, methane emission accompanied by generation of carbonate minerals or the like resulted in the higher sand content and lower moisture content. In contrast, the flat location (location 
No.3) had gas emissions, but they were low in activity and the location was high in clay matter, with little variance in particle size distribution in the depth direction, which may have resulted in the higher moisture content. In addition, where the depth exceeded $2.5 \mathrm{~m}$, differences in particle size distribution at different sampling locations were not recognized; therefore, differences in moisture content or strength were not recognized. In this way, it is thought that moisture content and strength properties differed as a result of topographical differences as well as sediment movement due to gas emissions from the lower seabed or due to resedimentation.

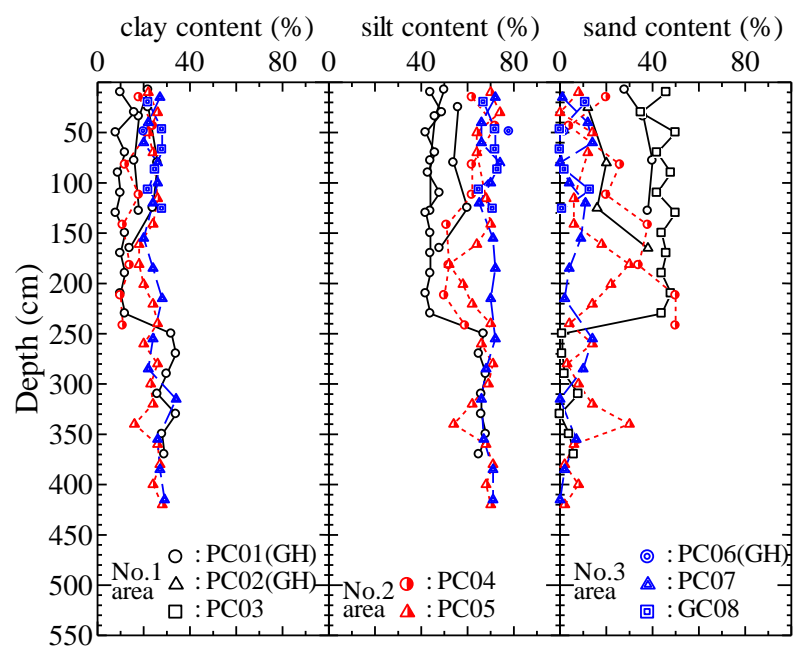

Fig. 9. Clay, silt and sand content of sea bottom sediments.

\section{CONCLUSION}

A survey of the Okhotsk Sea offshore of Abashiri found more than 200 locations of gas flares from the seabed, and gas-hydrates were successfully sampled. The presence of BSR was confirmed in a stretch of sea where seismic survey was performed, thus indicating the widespread presence of gas hydrates offshore of Abashiri in the Okhotsk Sea.

Depending on the sampling locations, the moisture content and strength properties of the sediment differed. This is thought to be the result of topographical differences, sediment movement due to gas emissions and hydrate generation from the lower seabed, and resedimentation.

\section{ACKNOWLEDGEMENTS}

We would like to thank Prof. H. Shoji, Prof. H. Minami, Dr. A. Hachikubo and Dr. H. Sakagami of Kitami Institute of Technology for their cooperation in the survey. We are also grateful to Captain T. Aoki, the officers and the crew of the R/V Natsushima, and Captain S. Takagi, the officers and the crew of the Oshoro-Maru, for skillful operations of the ship and research equipment. The research conducted on their cruise was partly supported by Kitami Institute of
Technology and Ministry of Education, Culture, Sports, Science and Technology through Grant-in Aid for Scientific Research.

\section{REFERENCES}

1) Satoh, M., Maekawa, T. and Okuda, Y. (1996): Estimation of amount of methane and resources of natural gas hydrate in the world and around Japan, Jour. Geol. Soc. Japan, 102(11), 959-971. (in Japanese)

2) Noda, A., Ikehara, K. and Katayama, H. (2009): Sedimentological map of Kitami-Yamato Bank, Marine Geology Map Series, 68 (CD), Geological Survey of Japan, AIST.

3) Yamashita, S., Matsumoto, R., Minami, H., Hachikubo, A., Hiromatsu, M., Tomaru, H., Okuda, Y., Shoji, H. and Takahashi, N. (2012): Marine surveys for gas-hydrate off Abashiri, the Sea of Okhotsk, Japan Geoscience Union Meeting 2012, Chiba, Japan, May 20-25.

4) Ogawa, K., Dewa, H., Yamashita, S., Sakagami, H., Yamasaki, S., Minami, N., Hachikubo, A., Shoji, H., Takahashi, N., Matsumoto, R. and Kataoka, S. (2013): Shallow gas-hydrate surveys and seabed soil properties off Abashiri, the Sea of Okhotsk, Proceedings of the 48th Japan National Conference on Geotechnical Engineering, Toyama, Japan, 493-494. (in Japanese)

5) Hayashi, M., Saeki, T., Inamori, T. and Noguchi, S. (2010): The distribution of BSRs related to methane hydrates, offshore Japan, Journal of the Japanese Association for Petroleum Technology, 75(1), 42-53. (in Japanese)

6) Ashi, J. and Taira, A. (1993): Thermal structure of the Nankai Accretionary Prism as inferred from the distribution of gas hydrate BSRs, Geological Society of America Special Paper 273, 137-149.

7) Sloan, E.D. and Koh, C.A. (2007): Clathrate hydrates of natural gases, 3rd ed, ISBN 978-0-8493-9078-4, CRC Press, 752p.

8) Machiyama, H., Kinoshita, M., Takeuchi, R., Matsumoto, R., Yamano, M., Hamamoto, H., Hiromatsu, M., Satoh, M. and Komatsubara, J. (2009): Heat flow distribution around the Joetsu gas hydrate field, Western Joetsu Basin, eastern margin of the Japan Sea, Journal of Geography, 118(5), 986-1007. (in Japanese)

9) Yamashita, S., Moriwaki, T., Hachikubo, A., Minami, H., Shoji, H., Kawaguchi, T. and Kataoka, S. (2011): Strength change of seabed soils due to the vaporization of dissolved gas in the pore water, Proceedings of the 5th International Symposium on Deformation Characteristics of Geomaterials, Seoul, Korea, 905-910. 